\title{
Effects of Atropine, Eserine and Tetramethylammonium on the Adrenal 17-Hydroxycorticosteroid Secretion in Anesthetized Dogs
}

\author{
Kensaku Otsuka \\ Department of Physiology (Prof. T. Suzuki), \\ Nagasaki University School of Medicine, Nagasaki
}

\begin{abstract}
Effects of atropine, eserine and tetramethylammonium (TMA) on the adrenal 17-hydroxycorticosteroid (17-OHCS) secretion in dogs anesthetized with sodium pentobarbital were directly evaluated. Atropine, eserine or TMA was administered intravenously. Eserine $(0.3 \mathrm{mg} / \mathrm{kg}$ of body-wt.) produced a marked increase in 17.OHCS secretion and the maximal secretion rate was mostly observed at 10 min after injection. TMA $(1.0 \mathrm{mg} / \mathrm{kg})$ induced also a definite increase in adrenal $17.0 H C S$ secretion, the maximal secretion rate being observed at 5 or $10 \mathrm{~min}$ after administration. Atropine $(1.0 \mathrm{mg} / \mathrm{kg})$ which had been proved to produce a marked increase in 17-OHCS secretion in conscious dogs had no effects on the secretion of 17-OHCS in dogs anesthetized with sodium pentobarbital.
\end{abstract}

The previous study in our laboratory with direct evaluation of adrenal 17hydroxycorticosteroid (17-OHCS) secretion in conscious dogs indicated that atropine, eserine, and tetramethylammonium (TMA) increased markedly the adrenal secretion of 17-OHCS., ${ }^{1}$ Some investigators indicated that sodium pentobarbital inhibited the stimulatory effects of morphine ${ }^{3-6}$ and aspirin ${ }^{5}$ but not the actions of histamine,,$^{5,6}$ adrenaline ${ }^{5,6}$ and insulin ${ }^{6}$ on the pituitary-adrenocortical system.

In view of these reports, the present study has been designed to know the effect of sodium pentobarbital anesthesia upon the adrenal 17-OHCS secretion in response to atropine, eserine, and TMA.

\section{METHODS}

Mongrel dogs, ranging from 7.4 to $12.1 \mathrm{~kg}$ in weight, were used. The adrenal venous blood was collected by a modification of the method of Satake and his co-workers. ${ }^{7}$ The animals were anesthetized by i.v. injection of sodium pentobarbital (Nembutal, Abbott) in a dose of $25 \mathrm{mg} / \mathrm{kg}$. Then the lumboadrenal vein was exposed through the lumbar route and the side branches of the vein were cut off between double ligatures. A small glass cannula connected with a short rubber

Received for publication, December 4, 1965. 
tube was inserted into the lumboadrenal vein just lateral to the adrenal gland. The cannula and the rubber tube were filled with heparine-saline solution. A silk thread was placed around the vein at the site between the adrenal gland and the inferior vena cava in order to make adrenal venous blood flow out through the cannula and rubber tube by pulling the thread at the period of the adrenal venous blood collection.

Approximately 20 hours or in some cases 4 hours after the adrenal vein cannulation, the animals were anesthetized again with i.v. sodium pentobarbital in a dose of $25 \mathrm{mg} / \mathrm{kg}$ of body-wt. A small glass cannula for the administration of chemicals was inserted into the saphenous vein. An hour after these procedures, the observation was started. After two adrenal venous blood samples for estimating resting secretion rates were collected, atropine, eserine or TMA was injected i.v. Atropine sulphate (Merck) or tetramethylammonium bromide (Merck) was injected i.v. in a dose of $1.0 \mathrm{mg} / \mathrm{kg}$ and eserine salicylate (Merck) in a dose of $0.3 \mathrm{mg} / \mathrm{kg}$. The adrenal venous blood samples were collected at 10, 25, 40,60, 90 , and $120 \mathrm{~min}$ after injection of atropine or eserine, and at 5, 10, 20,40,60, and 90 min after administration of TMA.

Immediately after adrenal venous blood collection, the samples were iced and centrifuged at 2,000 r.p.m. for $20 \mathrm{~min}$. Adrenal venous plasma was analyzed for 17-OHCS by the method of Nelson and Samuels. ${ }^{8}$

\section{RESULTS}

\section{Effect of atropine}

Atropine in a dose of $1.0 \mathrm{mg} / \mathrm{kg}$ was injected i.v. in $60 \mathrm{sec}$. No changes in respiratory movements were observed. The results concerning the adrenal 17OHCS secretion are shown in Table 1. In all cases but one $(\log 3)$ the 17-OHCS secretion rate was not increased by atropine under sodium pentobarbital anesthesia. In $\operatorname{dog} 3$ the secretion rate at $60 \mathrm{~min}$ after injection showed a high

TABLE 1. Effect of atropine on adrenal 17.OHCS secretion rate in dogs anesthetized with sodium pentobarbital

\begin{tabular}{|c|c|c|c|c|c|c|c|c|c|c|}
\hline \multirow{3}{*}{$\begin{array}{l}\text { Dog } \\
\text { and }\end{array}$} & \multirow{3}{*}{$\begin{array}{l}\text { No. } \\
\text { sex }\end{array}$} & \multirow{3}{*}{$\begin{array}{c}\text { Body-wt. } \\
(\mathrm{kg})\end{array}$} & \multicolumn{8}{|c|}{ Adrenal $17-\mathrm{OHCS}$ secretion rate $(\mu \mathrm{g} / \mathrm{kg} / \mathrm{min})$} \\
\hline & & & \multicolumn{2}{|c|}{$\begin{array}{l}\text { Min before } \\
\text { injection }\end{array}$} & \multicolumn{6}{|c|}{ Min after injection of atropine } \\
\hline & & & 30 & 10 & 10 & 25 & 40 & 60 & 90 & 120 \\
\hline 1 & \& & 9.6 & 0.41 & 0.18 & 0.25 & 0.24 & 0.19 & 0.20 & 0.19 & 0.22 \\
\hline 2 & $\hat{o}$ & 12.1 & 0.28 & 0.15 & 0.31 & 0.19 & 0.20 & 0.26 & 0.12 & 0.19 \\
\hline 3 & $\delta$ & 7.8 & 0.25 & 0.26 & 0.25 & 0.41 & 0.35 & 0.74 & 0.39 & 0.31 \\
\hline 4 & Q & 11.2 & 0.18 & 0.08 & 0.28 & 0.08 & 0.08 & 0.04 & 0.04 & 0.09 \\
\hline 5 & $\hat{\delta}$ & 7.7 & 0.11 & 0.13 & 0.10 & 0.18 & 0.29 & 0.22 & 0.07 & 0.22 \\
\hline 6 & $\delta$ & 10.4 & 0.13 & 0.36 & 0.37 & 0.22 & 0.12 & 0.06 & 0.15 & 0.36 \\
\hline 7 & 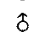 & 10.4 & 0.13 & 0.10 & 0.09 & 0.15 & 0.11 & 0.08 & 0.02 & 0.21 \\
\hline
\end{tabular}


level, but this will probably be due to an incompleteness of anesthesia.

\section{Effect of eserine}

Eserine in a dose of $0.3 \mathrm{mg} / \mathrm{kg}$ was administered i.v. in $30 \mathrm{sec}$. Deep and rough respiration was observed within $20 \mathrm{sec}$ after the start of injection without exception. Salivation and defecation occurred within $5 \mathrm{~min}$. As is presented in Table 2, an increased 17-OHCS secretion was found in all cases. The adrenal 17-OHCS secretion rate after injection of eserine showed the maximal value mostly at $10 \mathrm{~min}$ after injection and resumed the pre-injection level within 40-90 min. Only in one case, $\operatorname{dog} 10$ the secretion rate increased at $20 \mathrm{~min}$.

TABLE 2. Effect of eserine on adrenal 17-OHCS secretion rate in dogs anesthetized with sodium pentobarbital

\begin{tabular}{|c|c|c|c|c|c|c|c|c|c|c|}
\hline \multirow{3}{*}{\multicolumn{2}{|c|}{$\begin{array}{l}\text { Dog No. } \\
\text { and sex }\end{array}$}} & \multirow{3}{*}{$\begin{array}{c}\text { Body-wt. } \\
(\mathrm{kg})\end{array}$} & \multicolumn{8}{|c|}{ Adrenal $17-0 H C S$ secretion rate $(\mu \mathrm{g} / \mathrm{kg} / \mathrm{min})$} \\
\hline & & & \multicolumn{2}{|c|}{$\begin{array}{l}\text { Min before } \\
\text { injection }\end{array}$} & \multicolumn{6}{|c|}{ Min after injection of eserine } \\
\hline & & & 30 & 10 & 10 & 25 & 40 & 60 & 90 & 120 \\
\hline 8 & q & & 0.09 & 0.08 & 0.78 & 0.62 & 0.47 & 0.38 & 0.13 & 0.09 \\
\hline 9 & \& & & 0.30 & 0.20 & 1.22 & 0.68 & 0.99 & 0.15 & 0.13 & 0.15 \\
\hline 10 & $\delta$ & 9 & 0.24 & 0.28 & 0.12 & 0.64 & 0.10 & 0.09 & 0.12 & 0.16 \\
\hline 11 & \& & 9. & 0.17 & 0.05 & 1.60 & 0.76 & 0.19 & 0.23 & 0.12 & 0.10 \\
\hline 12 & \& & 7.4 & 0.07 & 0.16 & 1.02 & 1.07 & 0.23 & 0.10 & 0.08 & 0.13 \\
\hline
\end{tabular}

\section{Effect of TMA}

An i.v. administration of $1.0 \mathrm{mg} / \mathrm{kg}$ of TMA in $15 \mathrm{sec}$ resulted in a marked increase in adrenal 17-OHCS secretion in all cases. The results are summarized in Table 3. Within 10 sec after the start of TMA injection, respiration became frequent and deep, and then salivation occurred. These signs disappeared within a minute. Maximal secretion rate of $17-0 H C S$ occurred at 5 or $10 \mathrm{~min}$ and the preinjection level was resumed at 40 min after injection in all cases except $d o g 14$ in

TABLE 3. Effect of TMA on adrenal 17-OHCS secretion rate in dogs anesthetized with sodium pentobarbital

\begin{tabular}{|c|c|c|c|c|c|c|c|c|c|}
\hline \multirow{3}{*}{$\begin{array}{l}\text { Dog No. } \\
\text { and sex }\end{array}$} & \multirow{3}{*}{$\begin{array}{c}\text { Body-wt. } \\
\text { (kg) }\end{array}$} & \multicolumn{8}{|c|}{ Adrenal $17-0 H C S$ secretion rate $(\mu \mathrm{g} / \mathrm{kg} / \mathrm{min})$} \\
\hline & & \multicolumn{2}{|c|}{$\begin{array}{l}\text { Min before } \\
\text { injection }\end{array}$} & \multicolumn{6}{|c|}{ Min after injection of TMA } \\
\hline & & 30 & 10 & 5 & 10 & 20 & 40 & 60 & 90 \\
\hline 13 우 & 8.5 & 0.19 & 0.20 & 0.80 & 0.26 & 0.45 & 0.24 & 0.04 & 0.17 \\
\hline $14 \hat{\jmath}$ & 8.4 & 0.15 & 0.17 & 0.79 & 0.82 & 0.69 & 0.75 & 0.97 & 0.58 \\
\hline $15 ?$ & 9.3 & 0.22 & 0.20 & 1.07 & 1.14 & 0.27 & 0.11 & 0.08 & 0.07 \\
\hline 16 \& & 11.3 & 0.17 & 0.07 & 1.27 & 1.50 & 0.30 & 0.09 & 0.08 & 0.03 \\
\hline
\end{tabular}

TMA : tetramethylammonium 
which increased secretion of $17-0 H C S$ continued for $90 \mathrm{~min}$.

\section{DISCUSSION}

In the present investigation it was clarified that the adrenal 17-OHCS secretion in dogs anesthetized with sodium pentobarbital was increased by eserine and TMA, but not by atropine. In conscious dogs the adrenocortical responses to these agents were previously evaluated by almost the same procedure as described here. ${ }^{1,2}$ The average values of the 17-OHCS secretion rates in anesthetized and unanesthetized dogs after administration of atropine, eserine or TMA are illustrated in Fig. 1. Under sodium pentobarbital anesthesia the adrenal 17-OHCS secretion rate after atropine injection remained at low level, whereas in unanesthetized dogs a marked elevation of the level of 17-OHCS secretion was observed for more than $90 \mathrm{~min}$ (Fig. 1, A). Eserine had a stimulatory effect on the adrenocortical secretion both in unanesthetized and anesthetized dogs. However, the peak of the average values of 17-OHCS secretion rates in unanesthetized dogs was definitely higher than that in anesthetized dogs (Fig. 1, B). The effect of TMA on the adrenal 17-OHCS secretion rate in anesthetized dogs was similar with that in unanesthetized dogs, as is shown in Fig. 1, C.

As to the effects of eserine and atropine on the adrenal cortical secretion, Dordoni and Fortier ${ }^{9}$ showed that adrenal ascorbic acid depletion was induced in rats by eserine and atropine administered simultaneously or independently. Harwood and Mason ${ }^{10}$ found that in unanesthetized dogs eserine $(0.05 \mathrm{mg} / \mathrm{kg})$ produced a marked eosinopenia, but had no effects on the 17-OHCS level in peripheral blood. However, as the dose of eserine used by them is rather small and the 17-OHCS level in peripheral blood is a measure of the balance among production, metabolism, and excretion of the hormones, their negative results do not readily mean that eserine has no effects on the adrenal 17-OHCS secretion. Intravenous injection of TMA in a dose of $1.0 \mathrm{mg} / \mathrm{kg}$ has been proved to induce a marked increase in adrenaline secretion from the adrenal gland." However, it is not very convincing that an increase in adrenal 17-OHCS secretion causable by TMA might account for the stimulatory action of adrenaline on the pituitaryadrenocortical system, since adrenaline has no consistent effect on the adrenocortical secretion at least in the dog.

As concerns the effect of sodium pentobarbital on the pituitary-adrenocortical system, it has been reported that the adrenal ascorbic acid depletion in rats produced by morphine is inhibited by pretreatment of sodium pentobarbital. ${ }^{3-6}$ Harwood and Mason ${ }^{12}$ found in the monkey that the peripheral plasma level of 17-OHCS was depressed by sodium pentobarbital. An evidence of the inhibitory effect of sodium pentobarbital on the resting secretion of 17-OHCS in the dog was provided by Suzuki et al. ${ }^{13}$ Royce and Sayers ${ }^{14}$ demonstrated in rats a depressant action of sodium pentobarbital on the level of blood ACTH. They mentioned that 

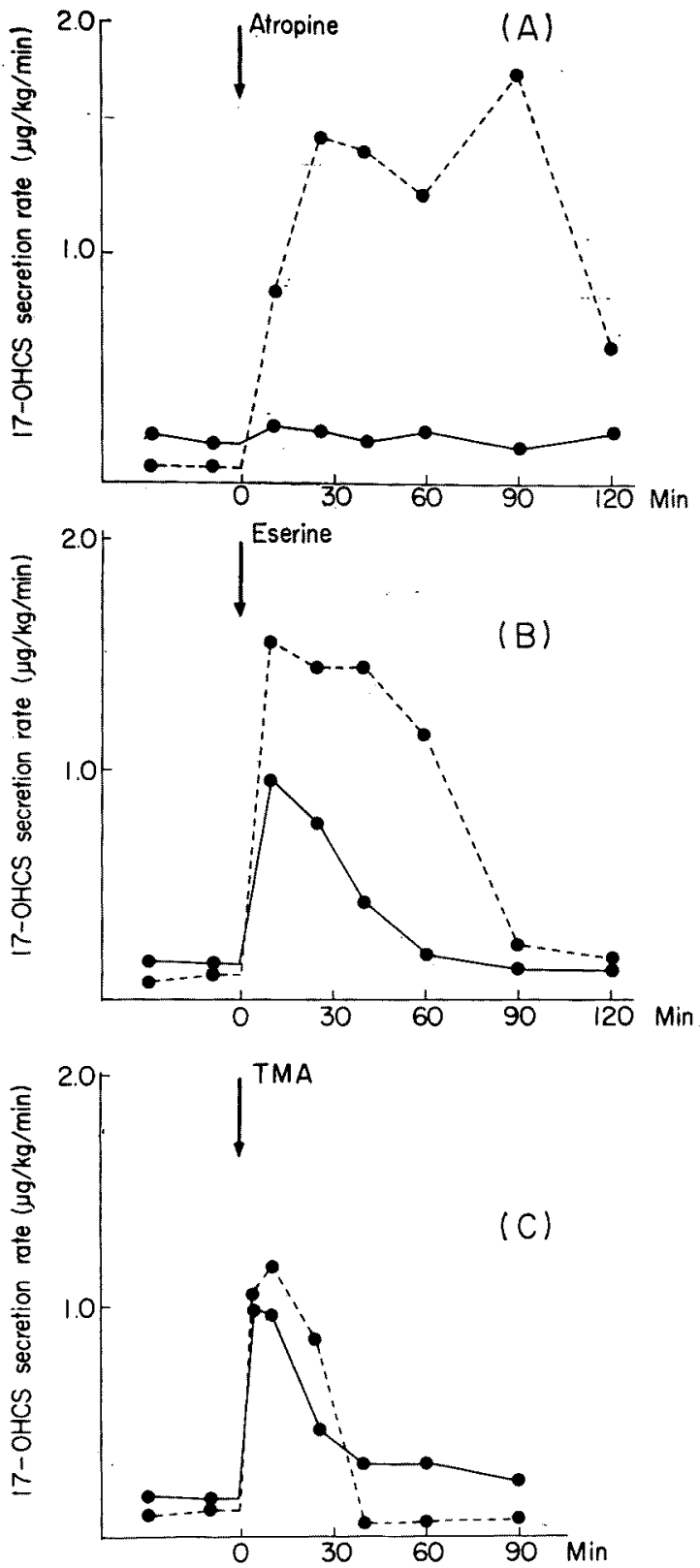

Fig. 1. Effects of atropine (A), eserine (B), and tetramethylammonium (C) on adrenal 17-hydroxycorticosteroid secretion rate in anesthetized and conscious dogs. The solid lines represent the average values in anesthetized dogs, and the dotted lines those in consoious dogs. 
it was reasonable to speculate that the sites of action of sodium pentobarbital in inhibiting ACTH release involve the brain stem reticular activating system.

In view of the inhibitory effect of sodium pentobarbital on the 17-OHCS secretion in response to atropine, it may be possible that sodium pentobarbital and atropine act on the same site of the central nervous system. However, there is another possibility that in conscious dogs atropine produces psychical excitment which in turn induces an increase in 17-OHCS secretion and this excitement is abolished by sodium pentobarbital anesthesia.

I wish to thank Professor Tatuzi Suzuki for his suggestions in this study and for his helpful oriticisms during the preparation of the manuscript.

\section{References}

1) Suzuki, T., Hirai, K., Yoshio, H., Kurouji, K-I. \& Hirose, T. Effect of eserine and atropine on adrenocortical hormone secretion in unanesthetized dogs. $J$. Endocrin., 1964, 31, 81-82.

2) Suzuki, T., Ohukuzi, S., Matsui, H. \& Otsuka, K. Effect of tetramethylammonium and potassium chloride on adrenal 17-hydroxycorticosteroid secretion in unanesthetized dogs. Tohoku J. exp. Med., 1965, 87, 259-261.

3) Briggs, F.N. \& Munson, P.L. Studies on the mechanism of stimulation of ACTH secretion with the aid of morphine as a blocking agent. Endocrinology, 1955, 57, 205219.

4) Ohler, E.A. \& Sevy, R.W. Inhibition of stress induced adrenal ascorbic acid depletion by morphine, dibenzyline and adrenal cortex extract. Endocrinology, $1956,59,347-355$.

5) Van Peenen, P.F.D. \& Way, E.L. The effect of certain central nervous system depressants on pituitary-adrenal activating agents. J. Pharmacol. exp. Ther., $1957,120,261-267$.

6) Mitamura, T. Effect of sodium pentobarbital anesthesia upon adrenal ascorbic acid depletion induced by morphine, histamine, adrenaline and insulin. Acta med. Nagasaki., 1960, 5, 63-66.

7) Satake, Y., Sugawara, T. \& Watanabe, M. A method for collecting the blood from the suprarenal gland in the dog, without fastening, narcotizing, laparotomy or provoking any pain. Tohoku J. exp. Med., 1927, 8, 501-534.

8) Nelson, D.H. \& Samuels, L.T. A method for the determination of 17hydroxycorticosteroids in blood: 17-Hydroxycorticosterone in the peripheral circulation. J. clin. Endocr., 1952, 12, 519-526.

9) Dordoni, F. \& Fortier, C. Effect of eserine and atropine on ACTH release. Proc. Soc. exp. Biol. (N.Y.), 1950, 75, 815-816.

10) Harwood, C.T. \& Mason, J.W. Effects of intravenous infusion of autonomic agents on peripheral blood 17-hydroxycorticosteroid levels in the dog. Amer. J. Physiol., 1956, 186, 445-452.

11) Goto, S. Effect of tetramethylammonium on the adrenal medullary secretion in the dog. Acta med. Nagasaki., 1960, 5, 108-115.

12) Harwood, C.T. \& Mason, J.W. Acute effeets of tranquilizing drugs on the anterior pituitary-ACTH mechanism. Endocrinology, 1957, 60, 239-246.

13) Suzuki, T., Yamashita, K., Kamo, M. \& Hirai, K. Effect of sodium pentobarbital and sodium hexobarbital anesthesia on the adrenal 17-hydroxycorticosteroid secretion rate in the dog. Endocrinology, 1962, 70, 71-74.

14) Royce, P.C. \& Sayers, G. Blood ACTH: Effects of ether, pențobarbital, epinephrine and pain. Endocrinology, 1958, 63, 794-800. 